\title{
Patient care and support measures overcome reluctance to initiate new regimen containing enfuvirtide
}

\author{
Benoit Trottier MD
}

B Trottier. Patient care and support measures overcome reluctance to initiate new regimen containing enfuvirtide. Can J Infect Dis Med Microbiol 2007;18(Suppl A):12A-13A.

Patients can be resistant to initiation of enfuvirtide therapy because of concerns about self-injection and related issues. Because the introduction of a new drug class can substantially enhance the efficacy of an antiretroviral regimen, supporting the patient in the introduction of enfuvirtide, a safe and efficacious agent in a new class, offers therapeutic benefits. In the present patient, who showed resistance to all three of the major antiretroviral drug classes, enfuvirtide was successfully introduced with clinic and peer support group assistance. The patient's acceptance was enhanced by the use of a needle-free injection system (Biojector), with minimal side effects and significantly improved virological and immunological control.

Key Words: Adherence; Enfuvirtide; HIV

Datients can be resistant to the initiation of enfuvirtide therapy because of the route of administration. Concerns about self-injection and travel can be overcome with a support and care system, which has been shown to have a significant effect on patient acceptance. As described in the following case, this approach allowed such a patient to add enfuvirtide to his therapy with beneficial effects.

\section{CASE PRESENTATION}

The patient, a 45-year-old man, was found to be HIV positive in 1994. He is otherwise healthy and is not coinfected with hepatitis B or C.

In April 1995, treatment with zidovudine was initiated. In February of the following year, lamivudine (3TC) was added to his treatment regimen, reflecting our knowledge of how to treat HIV patients at the time with a move from monotherapy to dual therapy. For the same reason, his therapy was further augmented with saquinavir in August 1996. This treatment failed, with the patient reaching his nadir CD4 count of $47 \mathrm{cells} / \mathrm{mm}^{3}$ on this therapy.

Treatment was re-evaluated and switched to a combination of stavudine, 3TC and indinavir. By July 1997, the patient's viral load was less than 500 copies/mL for the first time.

His viral load rebounded to 7800 copies/mL in November 1998. Nelfinavir replaced indinavir in his treatment regimen in January 1999. He subsequently developed severe diarrhea, and nelfinavir was replaced with indinavir boosted with ritonavir in May 1999.

Genotyping was performed in April 2000, and the patient was found to be highly resistant to nucleoside reverse transcriptase

\section{Vaincre la réticence à l'instauration d'un nouveau schéma à base d'enfuvirtide grâce aux soins aux patients et aux mesures de soutien}

Les patients peuvent être réticents à l'idée de commencer un traitement par l'enfuvirtide en raison de préoccupations relatives à l'auto-injection et à d'autres questions connexes. Étant donné que l'introduction d'une nouvelle classe de médicaments peut améliorer considérablement l'efficacité d'un schéma antirétroviral, appuyer le patient dans l'instauration de l'enfuvirtide, un agent sûr et efficace appartenant à une nouvelle classe, offre des bienfaits thérapeutiques. Dans le cas du présent patient, qui affichait une résistance aux trois grandes classes d'antirétroviraux, l'enfuvirtide a été ajouté avec succès au traitement grâce à un groupe d'aide par les pairs et à une assistance clinique. L'acceptation du patient a augmenté grâce à l'utilisation d'un système d'injection sans aiguilles (Biojector), avec des effets secondaires minimes et une amélioration significative du contrôle virologique et immunologique.

inhibitors (NRTIs) and protease inhibitors (PIs), with no mutations that indicated resistance to non-NRTIs. Based on these results, his previous therapy was switched in June 2000 to the combination treatment of abacavir, 3TC and zidovudine plus nevirapine. His response to this treatment was surprisingly minimal: his viral load never fell below 3500 copies/mL during the following year. In October 2001, nevirapine was replaced by efavirenz, lopinavir and ritonavir.

By December 2002, the patient's CD4 count had increased to 300 cells $/ \mathrm{mm}^{3}$ and his viral load was 2500 copies $/ \mathrm{mL}$. Genotyping was performed again, and he showed resistance to all antiretroviral (ARV) agent classes. Some susceptibility to tenofovir was indicated. Therefore, because the CD4 count was fairly stable and no better option was available, the decision was made to maintain him on the same regimen.

From 2003 to 2006, the patient's viral load fluctuated between 2000 copies $/ \mathrm{mL}$ and 6000 copies $/ \mathrm{mL}$, and his CD4 count decreased gradually from 300 cells $/ \mathrm{mm}^{3}$ to 225 cells $/ \mathrm{mm}^{3}$. He was offered participation in a variety of new drug trials, including enfuvirtide, CCR5 inhibitors, and a new PI and non-NRTI. He refused in each case because of his busy work schedule. Over this period, he became chronically depressed and desperate: he felt that new drugs would not save his life or benefit him because he had had an undetectable viral load only once in 10 years.

By March 2005, genotyping showed resistance to all three ARV drug classes, with eight mutations related to PIs and two mutations related to tenofovir. At this time, the patient was again offered participation in a trial - one with an investigational ARV agent and enfuvirtide. He was counselled that at least three active ARV agents are required to achieve the realistic goal of 
an undetectable viral load. Extensive information about enfuvirtide was provided: mechanism of action, mode of administration, absence of systemic side effects and management of injection site reactions.

He subsequently met with the clinic nurse, who provided explanations about enfuvirtide preparation and the self-injection procedure. To help him mentally prepare for self-administration, the patient did a practice injection with sterile water with the help of the nurse.

The patient still refused participation in the trial because of his reluctance to carry needles with him on his frequent business travel to the United States and to perform subcutaneous selfinjection.

He was then invited to attend a peer support group organized by a local support organization for those with HIV/AIDS. He agreed to participate. At those meetings, he came to realize that while enfuvirtide injection was not necessarily easy, other patients who used it were healthier than they had been before using it and seemed to be satisfied with it. One of the patients talked about his use of the Biojector (Biojector Medical Technologies, USA) for enfuvirtide injection, eliminating the use of needles.

The patient returned to the clinic and indicated his willingness to use enfuvirtide administered with the Biojector. His job situation had also changed and limited his business travel to Canada.
In April 2006, his CD4 count was 240 cells $/ \mathrm{mm}^{3}$ and his viral load was 5643 copies $/ \mathrm{mL}$. His new treatment regimen was initiated at that point, consisting of enfuvirtide plus tipranavir, ritonavir, tenofovir and 3TC. The following week, he returned to the clinic and met with the nurse, who reviewed the injection technique with him. He remained somewhat reluctant but gradually learned to perform the injections himself. His injection site reactions, mainly erythema and small nodules, were not severe and did not require analgesics to relieve the discomfort.

In June 2006, his viral load had dropped to less than 50 copies/mL for the first time, and his CD4 count had risen to 290 cells $/ \mathrm{mm}^{3}$. His condition again improved in July and November 2006 - his CD4 count increased to 320 cells $/ \mathrm{mm}^{3}$ and then to 380 cells $/ \mathrm{mm}^{3}$, and his viral load remained undetectable. The patient seemed very happy with this improved effectiveness of his therapy.

\section{COMMENTS}

This patient benefited substantially from the introduction of the new regimen including enfuvirtide. The reduction of viral load to undetectable levels with no significant side effects was very positive for the patient from both a physiological and a psychological perspective. 


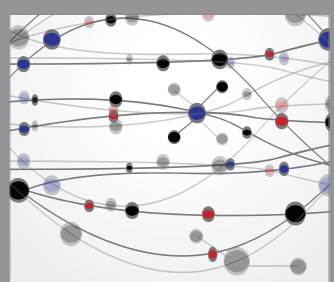

The Scientific World Journal
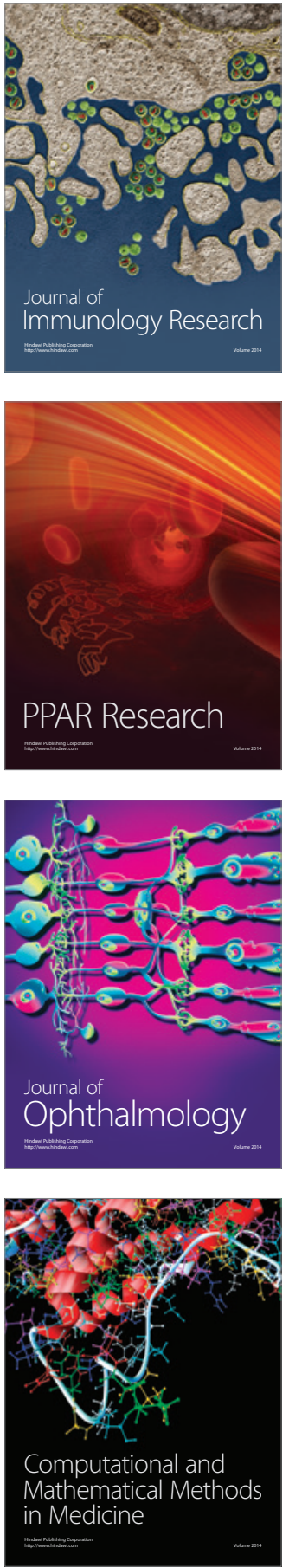

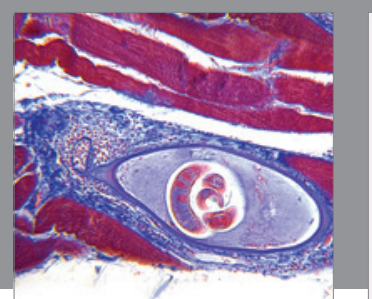

Gastroenterology Research and Practice

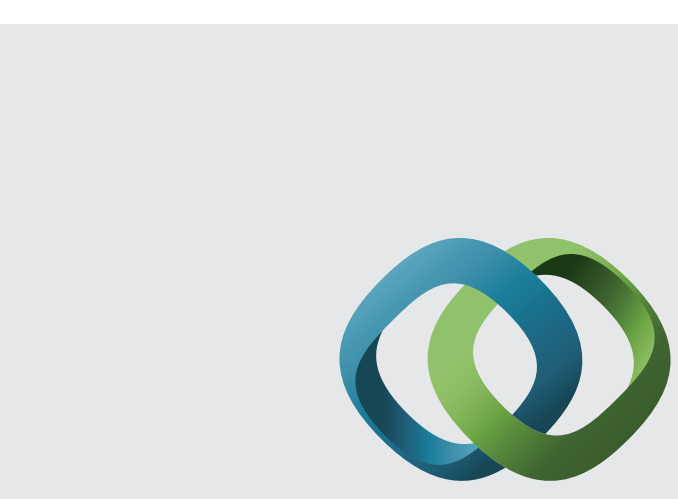

\section{Hindawi}

Submit your manuscripts at

http://www.hindawi.com
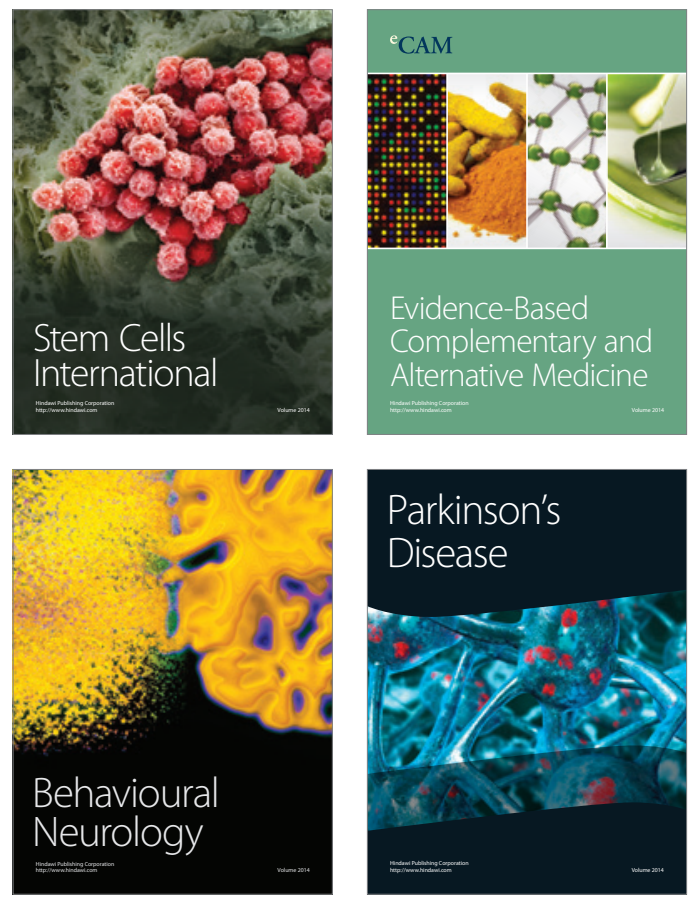
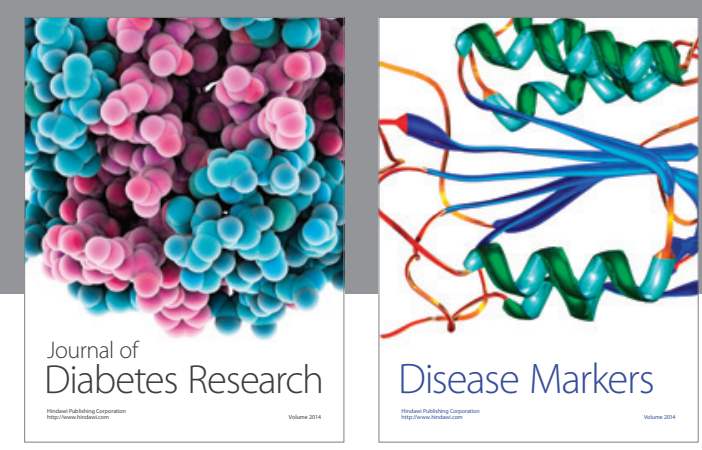

Disease Markers
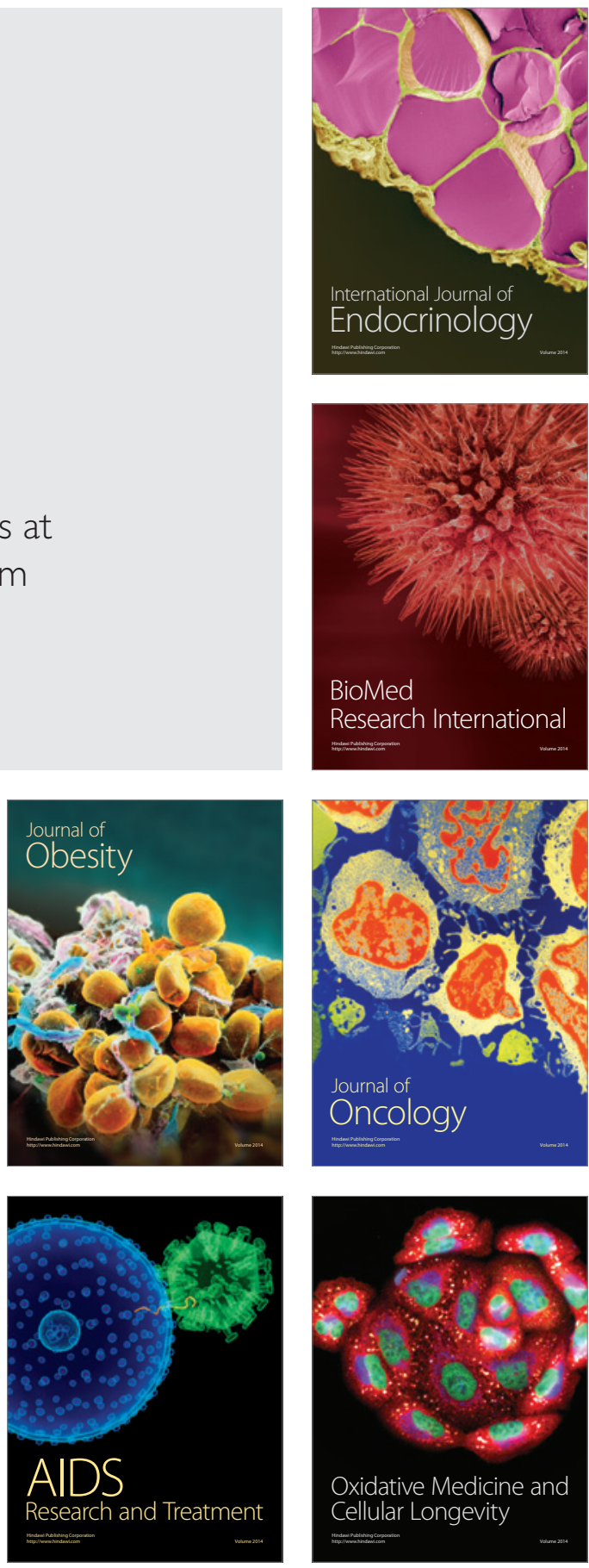